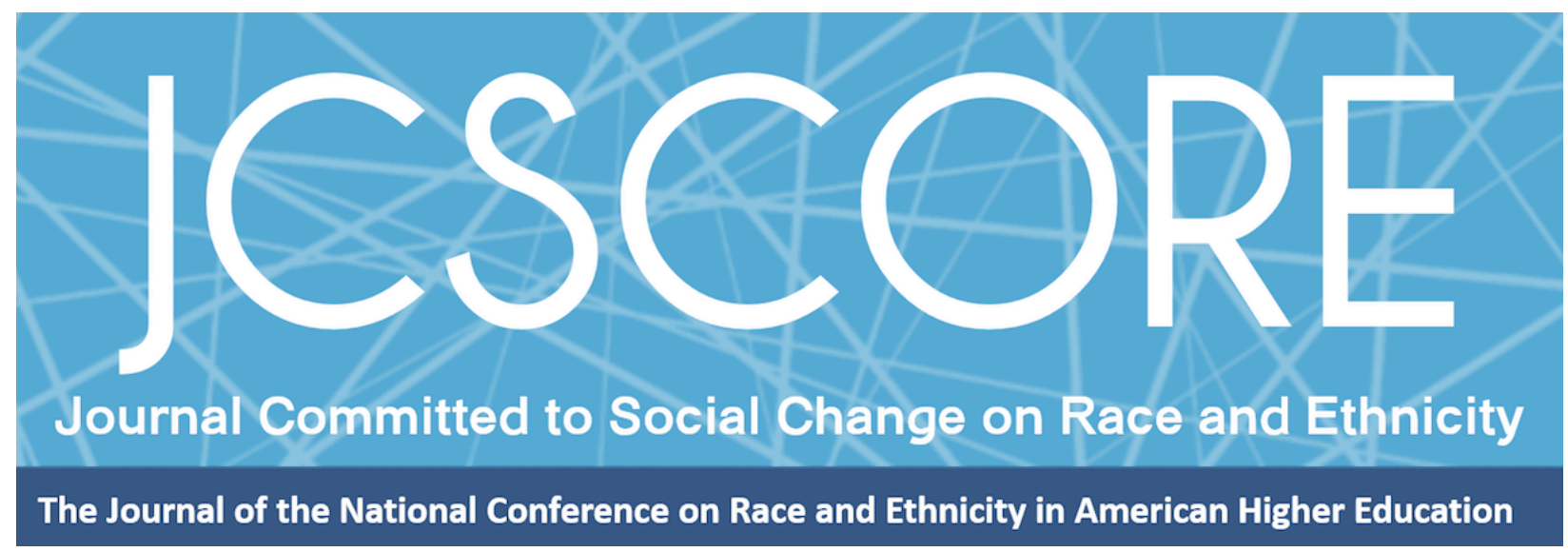

\title{
LETTER FROM THE EDITORS: A NEW BEGINNING
}

\author{
Bruce S. Busby, Editor-in-Chief
}

St. Cloud State University

Cristóbal Salinas Jr., Managing Editor

Florida Atlantic University

Kathleen Wong(Lau), Executive Operations Editor

Southwest Center for Human Relations Studies

University of Oklahoma Outreach

Belinda P. Biscoe, Executive Associate Editor

Southwest Center for Human Relations Studies

University of Oklahoma Outreach

Journal Committed to Social Change on Race and Ethnicity

Volume 1, Issue 1| 2015

Copyright @ 2015 Board of Regents of The University of Oklahoma on behalf of the Southwest Center for Human Relations Studies.

Permission of the Publisher is required for resale or distribution and for all derivative works, including compilations and translations. Quoting small sections of text is allowed as long as there is appropriate attribution. 


\section{Letter from the Editors: A New Beginning}

Bruce S. Busby, Editor-in-Chief

St. Cloud State University

Cristóbal Salinas Jr., Managing Editor

Florida Atlantic University

Kathleen Wong(Lau), Executive Operations Editor Southwest Center for Human Relations Studies University of Oklahoma Outreach

Belinda P. Biscoe, Executive Associate Editor Southwest Center for Human Relations Studies University of Oklahoma Outreach

We welcome you to the inaugural issue of the Journal Committed to Social Change on Race and Ethnicity (JCSCORE), the Journal of the National Conference on Race and Ethnicity in American Higher Education (NCORE). For over 28 years, NCORE has been a home for a multiplicity of approaches that support those educators who advocate and provide opportunities for underserved populations in higher education. We are honored and excited to continue championing these approaches that explore, examine, and report on the status of, and innovations in interventions, assessments, and progress on institutional change on race, ethnicity and sovereignty race in higher education. Through JCSCORE, we hope to share this conversation with a broader audience, to facilitate change and to raise the consciousness of our communities.

Research dedicated to the advancement of the study of race, ethnicity, and sovereignty on social justice in higher education and to its practical applications remains limited. Over the past two-years, Cristóbal Salinas Jr. explored the attitudes and opinions of NCORE participants on having a peer-reviewed, interdisciplinary journal affiliated with NCORE. The study reflects that NCORE participants are highly interested in reading and publishing in a journal affiliated with NCORE; one that supports, promotes and enhances research, ideas, issues, concerns, and promising practices for scholars, students, administrators, and faculty. Toward this end, we now launch JCSCORE: the Journal Committed to Social Change on Race and Ethnicity. 
Our mission is to promote an exchange of ideas that can transform lives, enhance learning, and improve human relations in higher education. We, the editors of JCSCORE, welcome quality, original, innovative manuscripts that address the interconnections of race, ethnicity and sovereignty in higher education policy, practice, and theory. As an interdisciplinary and peer-reviewed journal, we invite you to submit scholarship that transcends disciplinary boundaries including research articles and monographs, as well as creative papers that pursue innovative formats of scholarly work and approaches including narrative, poetry, and digital media.

The inaugural issue features innovative manuscripts from a range of scholars who have been asked to provide thought provoking essays to frame anew intellectual work on race, ethnicity and sovereignty in social justice in higher education. Manuscripts range from Mitchell J. Chang's memoir commentary, which interlaces historical events with civil rights legislation, calling for JCSCORE to "examine both the science that illuminates racial meaning and structures on the one hand and the art of rearranging meaning and inventing structures on the other hand" to Uma M. Jayakumar and Annie S. Adamian, who propose an understanding of affirmative action as having been raceconscious but never racism-conscious policy, with insights into how the current affirmative action and the diversity rationale did not move us backwards. Sylvia Hurtado, Adriana Ruiz Alvarado, and Chelsea Guillermo-Wann reexamine notions of student integration given continuing experiences of discrimination and bias on college campuses, and Tim Wise writes a reflection on Whiteness and American higher education. In addition, the inaugural issue features pieces from NCORE 2015 keynote speakers Adrienne Keene and Phil Yu.

We express our gratitude to the National Conference on Race and Ethnicity in American Higher Education, the Southwest Center for Human Relations Studies, and University of Oklahoma Outreach, for supporting JCSCORE. We thank Belinda P. Biscoe for her support in this project. Her positive attitude is our inspiration. We also thank our invited scholars and NCORE 2015 keynote speakers for their manuscripts. Last, we thank all of you for your support and interest in reading and publishing in JCSCORE. 